Original Research Paper

\title{
An Economic Perspective of the Export Potentiality of Aromatic Rice in Bangladesh
}

\author{
Riffat Ara Zannat Tama, Aurup Ratan Dhar and Ismat Ara Begum \\ Department of Agricultural Economics, Bangladesh Agricultural University, Mymensimgh-2202, Bangladesh
}

\author{
Article history \\ Received: 04-05-2018 \\ Revised: 05-05-2018 \\ Accepted: 5-07-2018 \\ Corresponding Author: \\ Aurup Ratan Dhar \\ Department of Agricultural \\ Economics, Bangladesh \\ Agricultural University, \\ Mymensimgh-2202, \\ Bangladesh \\ Email: aurup971@gmail.com
}

\begin{abstract}
The study was conducted to assess the export potential of aromatic rice in Bangladesh as well as identify the factors affecting gross return from aromatic rice production. About 45 aromatic rice farms were selected from five villages of Dinajpur district using stratified sampling method for the study. Data were analyzed with a combination of descriptive statistics, mathematical and statistical techniques. Cobb-Douglas production function represented that three out of seven independent variables had significant impact on gross return from aromatic rice production. The significant variables were education, power tiller cost and fertilizer cost. Domestic Resource Cost (DRC) analysis showed that Bangladesh had comparative advantage in aromatic rice production both from the view point of export and import substitution, as DRC was 0.51 and 0.64 for import and export parity prices, respectively. The study suggests that price of fertilizer, seeds and other inputs should be maintained and marketing and trade related costs and barriers should be minimized to amplify the potential of aromatic rice production in Bangladesh.
\end{abstract}

Keywords: Aromatic Rice, Production, Export, Comparative Advantage, Bangladesh

\section{Introduction}

Rice is the most important food crop of the developing world and the staple food of more than half of the world's population. More than 3.5 billion people depend on rice for more than $20 \%$ of their daily calories. In many Asian countries, rice consumption is very high, exceeding $100 \mathrm{~kg}$ per capita annually. A large number of middle to low-income Asian countries including the Philippines, Myanmar, Cambodia, Bangladesh and Laos continue to witness rising per capita consumption of rice. Although rice is consumed in the countries where it is produced, a growing demand in some areas is the international rice trade. In international rice trade, a relatively small number of exporting countries must interact with a large number of importing countries. In the first decade of the 2000s, the top five exporters had $81 \%$ of the world market (up from $69 \%$ in the 1960s) and since the 1980s, Thailand has consistently been the world's largest exporter of rice, followed by Vietnam and India. Because of the high volume of exports coming from only a few countries, the international rice market is vulnerable to disruptions in supply from major exporting countries, leading to higher world prices (Ricepedia, 2014).

In rice, aroma or scent is an inherent characteristic. In more scented rice varieties, it is apparent when the grains are smelled even when raw. Again, in lesser scented varieties, only cooking releases the aroma. Bangladesh produces a large number of rice varieties, ranging from coarse/medium to fine and aromatic rice grains. Aromatic rice attracts premium prices because it is highly valued by consumers, who use it for special purposes including feasts, religious occasions and so forth. Most of the aromatic rice varieties are grown in the Aman season, although quite a few are also grown in the Boro season (Talukder et al., 2004; Islam et al., 1996). The price of aromatic rice is two to three times higher than the level of ordinary long-grained rice of similar quality. Since 1992, Bangladeshi exporters have started exporting small quantities of aromatic rice mainly to the US. Kalijira, Kataribhog, Bansful, Chinigura are the mostly exported varieties of aromatic rice (Rahman, 2000).

It is now widely believed that Bangladesh can take advantage of earning valuable foreign exchange from export of aromatic rice. The argument in favor of 
exporting aromatic rice is strong even though the country is yet to produce any substantial surplus of rice. Export of a certain quantity of high-value aromatic rice will enable the country to import a much larger quantity of coarse or medium rice for local consumption. There have been sporadic attempts to export rice and there is evidence of export of limited quantities of aromatic rice to a number of countries. However, with a national point of view, whether or not a particular crop will be promoted for production will depend to a large extent on its comparative advantage in the export or import substitution proposition. This study tried to point out the determinants that influence the gross return from aromatic rice production. The researchers will find information from this study for conducting future investigations. The results of the study will also provide valuable information and clues to the policy makers in respect of production for domestic consumption and/or export of aromatic rice varieties. The specific objectives of the study were: (i) to determine the factors affecting gross return from aromatic rice production; and (ii) to analyze the export potential of aromatic rice varieties.

\section{Materials and Methods}

\section{Selection of Study Areas and Sample}

The study was conducted at five villages namely Borogram, Bosontopur, Indrapara, Krisnopur and Majhina from Chirirbandar upazila of Dinajpur district. At first, a list of 114 aromatic rice farmers were prepared, then categorized according to their farm size, that is marginal (land holdings 0.20 ha to $0.40 \mathrm{ha}$ ), small (land holdings 0.41 ha to $1.01 \mathrm{ha}$ ), medium and large farms (land holdings 1.02 ha to above ha). Based on this criterion, among total 114 farms, the number of marginal, small, medium and large farms was 42, 56 and 16 , respectively. 45 aromatic rice farms were selected from 114 farms by using stratified sampling method, by the ratio of the observation. That is why; the number of marginal, small, medium and large farms was 17, 22 and 6 , respectively according to land holdings. The varieties of aromatic rice locally named as Kataribhog, Kalijira, Chinigura, Badshabhog and Randhunipagol were considered in the study.

\section{Collection of Data and Information}

Data were collected by the researchers from February to April 2014 covering the cropping year of 2013. Field survey method using a structured questionnaire was followed to collect the primary data. Secondary data and information from different reports, publications, notifications, etc. relevant to this study were also collected and analyzed.

\section{Analytical Techniques}

An amalgamation of descriptive statistics, statistical and mathematical techniques was used to achieve the objectives of the study. Descriptive statistics like sum, averages percentages, etc. were calculated to represent the socioeconomic characteristics of the sample farmers. Cobb-Douglas production function was estimated to explore the factors affecting the gross return from aromatic rice production (Nerlove, 1965). To analyze the export potential of aromatic rice varieties, Domestic Resource Cost (DRC) approach was constructed (Bruno, 1972).

\section{Cobb-Douglas Production Function}

In order to estimate the effects of key variables in aromatic rice production, the Cobb-Douglas form of production function was used. The specification of the Cobb-Douglas production function for aromatic rice production was as follows:

$$
Y_{i}=a X_{1}^{b_{1}} X_{2}^{b_{2}} X_{3}^{b_{3}} X_{4}^{b_{4}} X_{5}^{b_{5}} X_{6}^{b_{6}} D_{1}^{b_{7}} e^{u}
$$

The Cobb-Douglas production function was transformed into following logarithmic form so that it could be estimated by the Ordinary Least Squares (OLS) method:

$$
\begin{aligned}
& \ln Y_{i}=\ln a+b_{1} \ln X_{1}+b_{2} \ln X_{2}+b_{3} \ln X_{3} \\
& +b_{4} \ln X_{4}+b_{5} \ln X_{5}+b_{6} \ln X_{6}+b_{7} D_{1}+U
\end{aligned}
$$

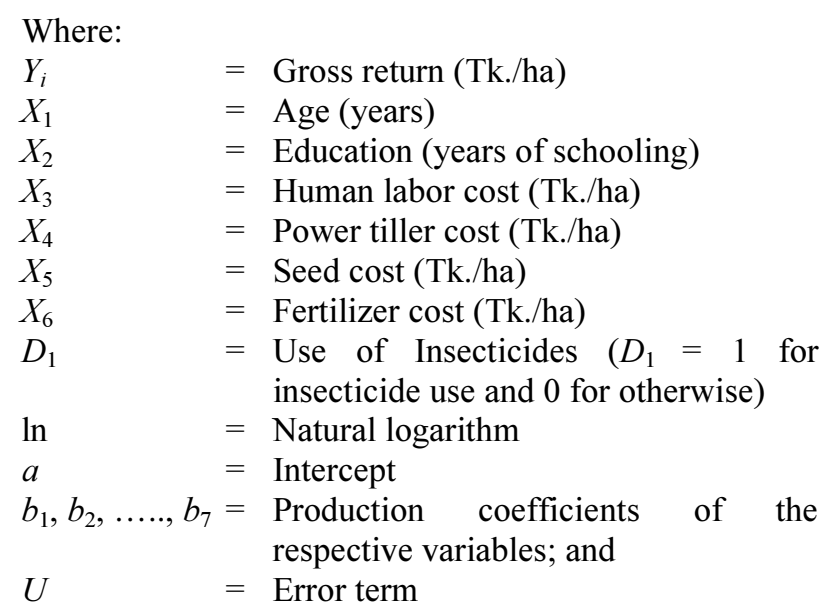

\section{Domestic Resource Cost (DRC) Analysis}

Domestic Resource Cost (DRC) approach was captured from Policy Analysis Matrix (PAM) and constructed to analyze the export potential of aromatic rice varieties from Bangladesh. The estimation of DRC can be a convenient method of generally assessing the comparative advantage of a single dominant crop in many Asian countries by indicating 
the economic profitability of keeping resources in its production instead of allocating them elsewhere (Anderson and Ahn, 1984). DRC is a measure of comparative advantage in the production of a commodity and represents the ratio of value added domestically in terms of opportunity cost or shadow price to value added at world price.

Comparative advantage expresses the efficiency of using resources to produce a particular product when measured against the possibilities of international trade. By comparing relative opportunity cost of producing a given commodity with the relative price at which the product can be traded, optimum pattern of production and trade for a country is determined. Production of those commodities should be reduced that can be imported at lower relative price and production of those product should be increased that can be produced at relatively lower costs (Anik, 2003).

This criterion used for determining the comparative advantage of aromatic rice was calculated by using the following equation (Bruno, 1972):

$$
\begin{aligned}
& D R C= \\
& \text { Cost of domestic resources and non traded } \\
& \frac{\text { inputs for producing per unit of output }}{\text { value of tradable output }- \text { value of tradable input }} \\
& =\frac{\sum f_{i j} P_{j}^{d}}{U_{i}-\sum a_{i k} P_{k}^{b}}(j=1,2, \ldots ., m ; k=1,2, \ldots . ., n)
\end{aligned}
$$

Where:

$f_{i j}=$ Domestic resource and non-traded inputs $j$ used for producing per unit commodity $i$

$P_{j}^{d}=$ Price of non-traded intermediate inputs and domestic resource

$U_{i}=$ Border price of output $i$

$a_{i k}=$ Amount of traded intermediate inputs for unit production of $i$

$P_{k}^{b}=$ Border price of traded intermediate input

If the DRC is greater than one, it implies that the economy loses foreign exchange through domestic production of aromatic rice because it consume more domestic resources than it generates net value added to tradable goods and services. Again when DRC is less than one, it implies that the production of aromatic rice is efficient and makes a positive contribution to domestic value added.

\section{Model Specification}

The estimates of the parameters of the models and the interpretation of these depend on the correct specification of the models. If an estimated model is not accurately specified, it will be biased and inconsistent
(Gujarati, 2003; Koutsoyiannis, 1997). That's why, some statistical inferences were used to test the validity of the models which confirmed the appropriateness and strength of the data used in the models.

\section{Jarque-Bera (JB) Test of Normality}

The JB test of normality is asymptotic or largesample test. It is also based on the OLS residuals. The test first computes the skewness and kurtosis measures of the OLS residuals and uses the following test-statistic:

$$
J B=n\left[\frac{S^{2}}{6}+\frac{(K-3)^{2}}{24}\right]
$$

Where:

$n$ = Sample size

$S=$ Skewness coefficient

$K=$ Kurtosis coefficient

For a normally distributed variable, $S=0$ and $K=$ 3. Therefore, the JB test of normality is a test of the joint hypothesis that $S$ and $K$ are 0 and 3, respectively. In that case, the value of the JB statistic is expected to be 0 . Under the null hypothesis that the residuals are normally distributed, JB test showed that asymptotically (i.e., in large samples) the JB statistic given above follows the chi-square distribution with 2 degrees of freedom. If the computed $p$ value of the JB statistic in an application is sufficiently low which will happen if the value of the statistic is very different from 0 , one can reject the hypothesis that the residuals are normally distributed. But if the $p$ value is reasonably large, which will happen if the value of the statistic is close to zero, normality assumption cannot be rejected (Gujarati, 2003). The result of Jarque-Bera test is presented in Fig. 1. Figure 1 shows that, JB = 9.484 and $\mathrm{P}=0.0087$. Considering the rounding figure of $\mathrm{P}$ value, $\mathrm{P}=0.01$, which is not less than 0.01 . So at $1 \%$ probability level, it was not significant. Thus it is confirmed that the residuals were normally distributed.

\section{Multicollinearity Test}

Multicollinearity means the existence of a 'perfect', or exact, linear relationship among some or all explanatory variables of a regression model. When multicollinearity exists in a model, there is very high standard error and low t statistics, unexpected changes in coefficient magnitudes or signs despite a high Rsquare. In this situation, the coefficient estimates may change irregularly in response to small changes in the model or in data.

The Variance Inflation Factor (VIF) is used to measure the multicollinearity. VIF measures how much 
the variance of the estimated coefficients increased over the case of no correlation among the $X$ variables. VIF can be defined as follows:

$$
V I F=\frac{1}{1-R_{i}^{2}}
$$

where, $R_{i}^{2}$ is the coefficient of determination or the regression of $X_{i}$ on the other covariates.

As a rule of thumb, if the VIF of a variable is greater than 10 , the variable is said to be highly collinear. Table 1 shows that the VIF of each explanatory variable as well as the mean VIF was very low. Thus, there existed no high multicollinearty in the model.

\section{Heteroscedasticity Test}

Heteroscedasticity occurs when the variance of the disturbance term is not constant, which is one of the most important assumptions of the classical linear regression model. In the presence of heteroscedasticity, coefficients remain unbiased, linear and consistent but inefficient. In order to test the heteroscedasticity problem, White's general heteroscedasticity test was used. This test showed that no heteroscedasticity was present in the data (Table 2). Obs*R-squared $/ \mathrm{chi}^{2}$ was not statistically significant as, $P$ $=0.20$. Thus, the null hypothesis may be accepted. That means there is no heteroscrdasticity in the data.

\section{Autocorrelation Test}

The assumption of OLS is that the random variable is independent. But if the value of random variable is correlated with its preceding value then autocorrelation arises. As the data were collected from aromatic rice growers, the data sets were cross sectional data. In case of cross sectional data, usually there is no autocorrelation.

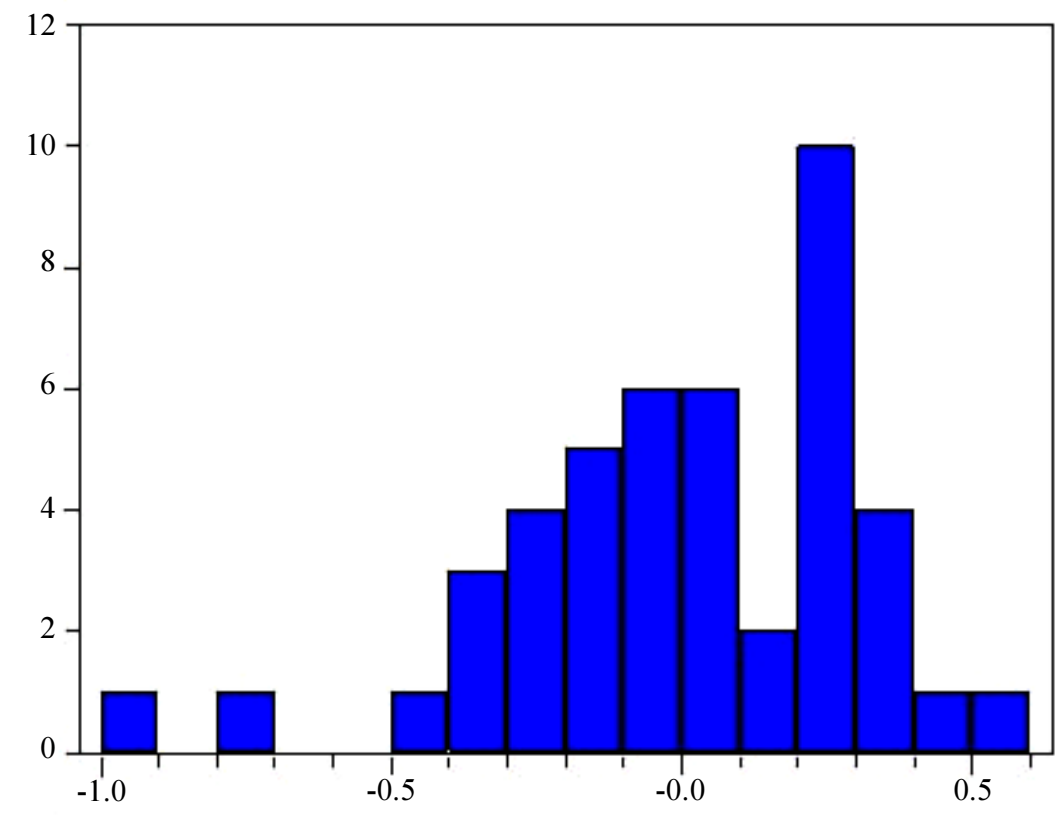

Series: Residuals

Sample 145

Observations 45

Mean

$2.95 \mathrm{e}-15$

Median

0.020466

Maximum

0.507817

Minimum

$-0.994635$

Std. Dev. $\quad 0.304643$

Skewness $\quad-0.925750$

Kurtosis $\quad 4.276836$

Jarque-Bera $\quad 9.484430$

Probability $\quad 0.008719$

Fig. 1: Jarque-Bera test of normality

Table 1: Multicollinearity test (VIF test)

\begin{tabular}{|c|c|c|c|c|}
\hline \multirow[b]{2}{*}{ Variables } & \multirow[b]{2}{*}{ t-value } & \multicolumn{2}{|c|}{ Collinearity statistics } & \multirow[b]{2}{*}{ Mean VIF } \\
\hline & & Tolerance & VIF & \\
\hline Age & 0.294 & 0.892 & 1.121 & 1.422 \\
\hline Education & 2.845 & 0.955 & 1.048 & \\
\hline Human labor & 0.067 & 0.684 & 1.461 & \\
\hline Power tiller & 3.736 & 0.563 & 1.775 & \\
\hline Seed & 0.322 & 0.524 & 1.907 & \\
\hline Fertilizer & 3.124 & 0.772 & 1.295 & \\
\hline Insecticide & -1.490 & 0.742 & 1.348 & \\
\hline
\end{tabular}

Source: Authors' estimation, 2014 
Table 2: White's general heteroscedasticity test

\begin{tabular}{|c|c|c|}
\hline $\mathrm{H}_{0}$ : There is no heter & & $p$-value \\
\hline F-statistic & 2.640085 & 0.052602 \\
\hline Obs*R-squared/chi ${ }^{2}$ & 40.48931 & 0.205665 \\
\hline
\end{tabular}

Source: Authors' estimation, 2014

\section{Results and Discussion}

\section{Factors Influencing Gross Return from Aromatic Rice Production}

To identify and measure the effects of the factors of production on gross return from aromatic rice production, Cobb-Douglas form of production function was estimated. Seven independent variables namely, age, education, human labor cost, power tiller cost, seed cost, fertilizer cost and use of insecticides were selected to explain the gross return from aromatic rice. Findings from a log-linear specification are represented in Table 3. The estimated Cobb-Douglas production function for aromatic rice was:

$$
\begin{aligned}
& \ln Y=3.810+0.060 \ln X_{1}+0.195 \ln X_{2}+0.006 \ln X_{3} \\
& +0.690 \ln X_{4}+0.039 \ln X_{5}+0.123 \ln X_{6}-0.179 \ln D_{1}
\end{aligned}
$$

\section{Explanation of Explanatory Variables}

The estimates of Cobb-Douglas production model show that age, education, human labor cost, power tiller cost, seed cost and fertilizer cost had positive impact; and use of insecticides had negative impact on gross return from aromatic rice production. The significant variables found from the model were education, power tiller cost and fertilizer cost (significant at $1 \%$ probability level, respectively). The results indicate that if age, education, human labor cost, power tiller cost, seed cost and fertilizer cost is increased by 1 percent, gross return from aromatic rice production will be increased by $0.060,0.195$, $0.006,0.690,0.039$ and 0.123 percent, respectively, holding other factors constant. On the contrary, if the use of insecticides is increased, the gross return from aromatic rice production will be increased, keeping other factors the same (Table 3 ).

Rahim (2004) supported the findings faintly by stating that the coefficients of seed, fertilizer and cowdung were positive and significant in the case of Basmoti, BRRI Dhan 28 and BRRI Dhan 29; and the coefficients of seed, animal labor, power tiller and irrigation were positive and significant in case of BRRI Dhan 28 and BRRI Dhan 29.

\section{Values of $R^{2}$ and Adjusted $R^{2}$}

The coefficient of determination, $\mathrm{R}^{2}$ is a summary measure, which tells how well the sample regression line fits the data. The estimated value of coefficient of multiple determination, $\mathrm{R}^{2}$ of the model was 0.648 which means that the explanatory variables included in the model explained $64.8 \%$ of the explained variable (i.e., gross return from aromatic rice production). The value of adjusted $\mathrm{R}^{2}$ was 0.582 indicating that after taking into account the degrees of freedom (df), the explanatory variables of the model still explain $58.2 \%$ of the dependent variable. So, the fitness of the model was satisfactory (Table 3).

\section{Goodness of Fit (F-Value)}

F-value indicates the overall significance of the model. It is evident from Table 3 that the F-value was 9.750 which was significant at 1 percent probability level. The findings indicated that the model was well fit and all the included variables were important for explaining the variation in gross return from aromatic rice production.

\section{Return to Scale}

Return to scale (RTS) reflects the degree to which a proportional change in all inputs causes a change in the output. Empirical analysis of production investigates RTS by estimating the total elasticity of production (i.e., sum of the estimated coefficients). When the total elasticity of production is equal to 1 , it indicates constant returns to scale; when it is greater than 1, it indicates increasing return to scale; and when it becomes less than 1 , it refers to decreasing return to scale. Return to scale for aromatic rice (0.933) was less than unity. It implies that aromatic rice growers were operating their production in decreasing return to scale. But it was almost near to constant return to scale. This result is consistent with Nasrin (2013).

\section{Export Potential of Aromatic Rice Varieties}

The study assessed the competitiveness of aromatic rice at farm gate level in the study areas through Domestic Resource Cost (DRC) analysis. Thai fragrant $4 \%$ was considered as the representative variety for the varieties of Kataribhog, Kalijira, Chinigura, Badshabhog and Randhunipagol, per ton price of which was US\$ 1180. Free on Board (FOB) prices of fertilizers (urea, TSP and MP) were collected from Bangladesh Bank. The main sources of secondary data were various publications of the Bangladesh Bureau of Statistics (BBS), Bangladesh Bank, Food and Agriculture Organization (FAO) and International Food Policy Research Institute (IFPRI). In addition, various unpublished sources were also extensively used. 
Table 3: Estimated values and statistics of Cobb-Douglas production model

\begin{tabular}{llll}
\hline Explanatory variables & Estimated coefficients & Standard errors & t-value \\
\hline Intercept & 3.810 & 1.35 & 2.83 \\
Age $\left(\mathrm{X}_{1}\right)$ & 0.060 & 0.19 & 0.29 \\
Education $\left(\mathrm{X}_{2}\right)$ & $0.195^{* * *}$ & 0.07 & 2.85 \\
Human labor cost $\left(\mathrm{X}_{3}\right)$ & 0.006 & 0.09 & 0.07 \\
Power tiller cost $\left(\mathrm{X}_{4}\right)$ & $0.690^{* * *}$ & 0.18 & 3.74 \\
Seed cost $\left(\mathrm{X}_{5}\right)$ & 0.039 & 0.12 & 0.32 \\
Fertilizer cost $\left(\mathrm{X}_{6}\right)$ & $0.123 * * *$ & 0.04 & 3.12 \\
Use of insecticides $\left(\mathrm{D}_{1}\right)$ & -0.179 & 0.12 & -1.49 \\
$\mathrm{R}^{2}$ & 0.648 & & \\
Adjusted $\mathrm{R}^{2}$ & 0.582 & & \\
F-value & $9.750^{* * *}$ & & \\
Return to scale & 0.933 & & \\
\hline Source: Aut & & & \\
\hline
\end{tabular}

Source: Authors' estimation, 2014; Note: ${ }^{* * *}$ indicates significant at 1 percent probability level

The choice of appropriate economic prices (shadow) for valuation of crop output should depend in principle on the assumption regarding whether additional output will be used for export or import substitution of domestic consumption. In practice, because of trade restriction and lack of market integration, it is not often easy to make a clear distinction in this respect. Bangladesh is exporting rice in small quantities from 1998/99. But still Bangladesh imports rice more than the export (Anik, 2003). Considering all these, import and export parity of rice were estimated. Inputs were divided into tradable and non-tradable inputs.

\section{Tradable Intermediate Inputs}

Tradable intermediate inputs are those inputs which are either exported or imported. In Bangladesh, it would be plausible to consider chemical fertilizers such as urea, TSP and MP as tradable intermediate inputs. Since Urea is both exported and imported, both export and import parity price were calculated. But in case of TSP an MP, only import parity price was considered because these two inputs are imported. Some other inputs such as irrigation equipments and pesticides are also imported but detailed cost of production figures for irrigation equipment were not available and pesticides constituted a small portion of the total cost of production, as a result these two items were not considered. The costs of fertilizers were measured in terms of border price.

\section{Non-Tradable Intermediate Inputs and Domestic Resources}

The resources that have the mobility within the country and not used in the international market are considered as non-tradable intermediate inputs and domestic resources. In Bangladesh, unskilled agricultural labor, animal power, land, seed, manure, irrigation charge and interest on operating capital belong to this category. The costs on these items were obtained from the field survey.

\section{Shadow Pricing of Inputs for DRC Analysis}

Land: Rental value of per unit land was applied for calculating the shadow price of land; labor: Market wage rate was considered for shadow pricing because no imperfect substantial market exists in agricultural labor market; working capital: Interest rate for working capital; fertilizers: International prices were used to calculate the import parity prices; and seed: Actual market price.

\section{Import Parity of Aromatic Rice}

The FOB price of aromatic rice was collected from FAO (2014). In this study, Dhaka was taken as wholesale market for aromatic rice because marketing, import and export routed and centered through Dhaka (supported by Huda, 2001; Mahmud et al., 1994). The FOB price was converted to Cost, Insurance and Freight (CIF) by adding ocean freight cost. Freight cost was collected from Kazal et al. (2013). Then the CIF price of selected crops at Chittagong plus transport cost from Chittagong to Dhaka, import handling cost and domestic trading cost less cost from mill gate to wholesale represented the border price at mill gate. From this, milling cost was subtracted by adjusting milling rate $67 \%$ (Kazal et al., 2013). In case of rice, cost from mill gate to wholesale, milling cost and cost from farm gate to mill gate were collected from Dewan (2011). Since the import handling cost was not found, this cost was considered $3 \%$ of CIF prices of aromatic rice (Huda, 2001). The import parity border price of aromatic rice is presented in Table 4 .

\section{Export Parity of Aromatic Rice}

World price (FOB Chittagong price) equals FOB Bangkok price minus the freight from Bangkok to Chittagong. Freight rate and FOB Bangkok price were the same as in the case of import parity. Border price measured at farm gate equals world price times official 
exchange rate less export handling and transportation cost less domestic trading costs less cost from mill gate to wholesale. Then milling cost was subtracted. The costs from farm gate to mill gate are subtracted to yield border price at farm gate. Export handling cost was considered 3\% of c.i.f. price of aromatic rice (Kazal et al., 2013; Huda, 2001). Calculation of export parity border price is presented in Table 5 .

Table 4: Import parity of aromatic rice in Bangladesh

\begin{tabular}{ll}
\hline Particulars & Amount (in Tk./mt) \\
\hline A. CIF price at Chittagong (US\$/mt) & 1236 \\
B. CIF price at Chittagong (Tk./mt) & 96099 \\
C. Marketing margin from the port of entry to the wholesale market & 4051.08 \\
Import handling cost & 2882.97 \\
Transportation cost & 1016.00 \\
Domestic trading cost & 152.11 \\
Border price at wholesale level (B + C) & 100150.1 \\
E. Components of the marketing spread between the wholesale market to the produce level & 46535.94 \\
Cost from mill gate to wholesale & 994.25 \\
Milling cost & 4242.5 \\
Adjustment at 67\% milling rate & 40060.03 \\
Interest cost & 474.1595 \\
Cost from farm gate to mill gate & 765 \\
F. Border price of farm produce at farm gate (D - E) & 53614.14
\end{tabular}

Source: Authors' estimation, 2014

Table 5: Export parity of aromatic rice in Bangladesh

\begin{tabular}{ll}
\hline Particulars & Amount (in Tk./mt) \\
\hline A. CIF price at port of exit Chittagong (US $\$ / \mathrm{mt})$ & 1124 \\
B. CIF price at port of exit Chittagong (Tk./mt) & 87391 \\
C. Components of the marketing margin from port of entry to wholesale market & 3789.84 \\
Export handling cost & 2621.73 \\
Transportation cost & 1016.00 \\
Trading cost & 152.11 \\
D. Border price at wholesale level (B-C) & 83601.16 \\
E. Components of the marketing spread between the wholesale market to the producer level & 39916.37 \\
Cost from mill gate to wholesale & 994.25 \\
Milling cost & 4242.5 \\
Adjustment at $60 \%$ milling rate & 33440.46 \\
Interest cost & 474.16 \\
Cost from farm gate to mill gate & 765 \\
F. Border price of farm produce at farm gate (D-E) & 43684.79 \\
\hline
\end{tabular}

Source: Authors' estimation, 2014

Table 6: Calculation of DRC (import parity) of aromatic rice in Bangladesh

\begin{tabular}{lr}
\hline Particulars (social prices) & \multicolumn{1}{c}{$\begin{array}{c}\text { Amount } \\
\text { (in Tk./mt) }\end{array}$} \\
\hline A. Value of tradable inputs (Tk./mt) & 3818.44 \\
B. Value of non-tradable inputs (Tk./mt) & 25463.52 \\
Human labor & 9049.87 \\
Power tiller cost & 1949.20 \\
Seed & 943.86 \\
Manure & 400.86 \\
Insecticide & 230.86 \\
Irrigation & 1571.53 \\
Interest on operating capital & 1115.40 \\
Rental value of land & 10202.09 \\
C. Output price & 53614.14 \\
D. Value added (tradable) (C - A) & 49795.70 \\
E. DRC (B $\div$ D) & 0.51 \\
\hline SOurc: Authors estmation 2014
\end{tabular}

Source: Authors' estimation, 2014
Table 7: Calculation of DRC (export parity) of aromatic rice in Bangladesh

\begin{tabular}{lr}
\hline Particulars (social prices) & $\begin{array}{c}\text { Amount } \\
\text { (in Tk./mt) }\end{array}$ \\
\hline A. Value of tradable inputs (Tk./mt) & 3818.44 \\
B. Value of non-tradable inputs (Tk./mt) & 25463.52 \\
Human labor & 9049.87 \\
Power tiller cost & 1949.20 \\
Seed & 943.86 \\
Cowdung & 400.86 \\
Insecticide & 230.68 \\
Irrigation & 1571.53 \\
Interest on operating capital & 1115.40 \\
Land use costs & 10202.09 \\
C. Output price & 43684.79 \\
D. Value added (tradable) (C-A) & 39866.35 \\
E. DRC (B $\div$ D) & 0.64 \\
\hline
\end{tabular}

Source: Authors' estimation, 2014 
Table 8: DRC (import and export parity) of aromatic rice in terms of Tk. per US\$

\begin{tabular}{|c|c|c|c|c|c|}
\hline \multirow[b]{2}{*}{ Item } & \multicolumn{2}{|c|}{ DRC (Tk./US\$) } & \multirow[b]{2}{*}{ Official Exchange Rate (OER) } & \multicolumn{2}{|l|}{ Direction } \\
\hline & Import parity & Export parity & & Import parity & Export parity \\
\hline Aromatic rice & 39.65 & 49.76 & 77.75 & DRCD OER & DRCL OER \\
\hline
\end{tabular}

Source: Authors' estimation, 2014; BBS, 2014

\section{Comparative Advantage Estimation}

Table 6 and 7 illustrate the values of inputs and output which were divided into traded and non-traded inputs and domestic resource items. Tradable inputs were valued at their world prices which were equivalent at farm level. The FOB prices of three types of fertilizer, urea, TSP and MP in 2013 were 340.13, 382.06 and 324.90 respectively which were collected from BB (2014). Table 6 shows the DRC considering import parity price which was 0.51 and Table 7 shows the DRC considering export parity price was 0.64 .

Table 8 shows DRC (import and export parity) for aromatic rice on the basis of Tk. per US\$. DRC considering import parity price on the basis of Tk. per US\$ was 39.65, which was lower than official exchange rate and DRC considering export parity price was 49.76 which was also lower than official exchange rate. Thus the results of the study implied that production of aromatic rice for import substitution and export, the case being stronger for import substitution than for export. The findings are quite similar with Rashid et al. (2009) where the author declared that Bangladesh had comparative advantage in rice production for import substitution and export promotion.

\section{Conclusion}

The study suggests that Bangladesh has efficiency in domestic aromatic rice production. In addition, Bangladesh can produce aromatic rice for export at higher price. The study reveals that education, power tiller cost and fertilizer cost (especially urea and MoP) had significant impact on gross return from aromatic rice production. Considering the findings of the study, some policy recommendations can be made: The policymakers are required to maintain the price of fertilizer, seeds and other inputs within the reach of the farmer, to reduce domestic cost of production and to minimize marketing and trade related costs and barriers if the economic profitability of aromatic rice is to get improved.

\section{Acknowledgement}

The authors express their earnest gratitude to the respondents and stakeholders of the study areas for their alliance and assistance in conducting surveys and collecting the data and information.

\section{Author's Contributions}

Riffat Ara Zannat Tama: Designed, collected and checked the analyzed data; prepared the draft manuscript and approved the final manuscript.

Aurup Ratan Dhar: Reviewed the draft manuscript, prepared the draft manuscript and contributed in data interpretation.

Ismat Ara Begum: Coordinated the study, analyzed the data and supervised the draft manuscript.

\section{Ethics}

This article is original and contains unpublished material. The corresponding author confirms that all of the other authors have read and approved the manuscript and no ethical issues involved.

\section{References}

Anderson, K. and I.C. Ahn, 1984. Protection policy and changing comparative advantage in Korean agriculture. Food Res. Stud., 19: 139-151.

Anik, A.R., 2003. Economic and financial profitability of aromatic and fine rice production in Bangladesh. MS Thesis, Bangladesh Agricultural University, Mymensingh, Bangladesh.

BBS, 2014. Monthly economic trends. Statistics Department, Bangladesh Bank, Dhaka, Bangladesh.

Bruno, M., 1972. Domestic resource costs and effective protection: Clarification and synthesis. J. Political Economy, 80: 16-33. DOI: 10.1086/259858

Dewan, M.F., 2011. A study on rice marketing system in Bangladesh with time series and cross-sectional data. MS Thesis, Bangladesh Agricultural University, Mymensingh, Bangladesh.

FAO, 2014. FAO rice price update. Food and Agriculture Organization of the United Nations.

Gujarati, D.N., 2003. Basic Econometrics. McGraw-Hill, New York.

Huda, F.A., 2001. Analysis of protection and comparative advantage of selected agricultural commodities in Bangladesh. MS Thesis, Bangladesh Agricultural University, Mymensingh, Bangladesh.

Islam, M.R., B.A.A. Mustafi and M. Hossain, 1996. Socioeconomic aspects of fine rice cultivation in Bangladesh. IRRI-RRRI Collaborative Research Report, AED, BRRI, Bangladesh. 
Kazal, M.M.H., S. Rahman, M.J. Alam and S.T. Hossain, 2013. Financial and economic profitability of selected agricultural crops in Bangladesh. National Food Policy Capacity Strengthening Programme (NFPCSP).

Koutsoyiannis, A., 1997. Theory of econometrics: An introductory exposition of econometric methods. Macmillan Press Limited, London.

Mahmud, W., S.H. Rahman and S. Zohir, 1994. Agricultural growth through crop diversification in Bangladesh. Food Policy in Bangladesh, Working Paper No. 7, International Food Policy Research Institute (IFPRI), Washington, D.C.

Nasrin, J., 2013. Financial profitability of aromatic rice production and its impacts on farmers' livelihood in selected areas of Tangail district. MS Thesis, Bangladesh Agricultural University, Mymensingh, Bangladesh.

Nerlove, M., 1965. Estimation and Identification of Cobb-Douglas Production Functions. 1st Edn., Rand McNally and Company, pp: 193.
Rahim, M.R., 2004. Profitability of some newly introduced rice varieties in selected locations of Bangladesh. MS Thesis, Bangladesh Agricultural University, Mymensingh, Bangladesh.

Rahman, M., 2000. Rationale and mechanics of rice exports from Bangladesh. Working Paper No. 4, Food Management and Research Support Project (FMRSP), Ministry of Food, Government of the People's Republic of Bangladesh.

Rashid, M.A., M.K. Hasan and H. Rashid, 2009. Domestic and international competitiveness of production of selected crops in Bangladesh. Final Report CF 1/08, National Food Policy Capacity Strengthening Programme.

Ricepedia, 2014. International rice market/trade.

Talukder, R.K., A.H. Sarker and A. Aziz, 2004. Potential of exporting aromatic and fine quality rice from Bangladesh. Final report, Bangladesh Rice Foundation. 